\title{
Students' Readiness to Organize Control Based on Gaming Technology According to the Motivational Criterion
}

\section{Yekaterina MASLIEVA}

Senior Teacher

Foreign Languages Department

Institute of Social Sciences and International Relations

Sevastopol State University

33, Universitetskaya str., Sevastopol, 299000, the Russian Federation

$+79787094585$

$\underline{\text { maslieva_k@rambler.ru }}$

\author{
Irina OSADCHAYA \\ Senior Teacher \\ Theory and Practice of Translation Department \\ Institute of Social Sciences and International Relations \\ Sevastopol State University \\ 33, Universitetskaya str., Sevastopol, 299000, the Russian Federation \\ $+79787094583$ \\ osadchayalis@mail.ru
}

\begin{abstract}
The article is devoted to the review of experimental scientific study results in the field of professional future English teachers training according to motivational criterion. During the study of successful student training pedagogical conditions in the sphere of control organization of younger pupils' educational achievements on the basis of gaming technologies were developed. In addition, selected criterion and indicators of future teacher readiness were defined. Comparative quantitative and qualitative analysis of the research results showed an increase in the level of readiness of respondents of experimental groups to the mentioned above training. It was found that in the experimental groups there were significant positive changes in the field of game control organization. In the control group there were positive changes too, although they were less significant. Summarizing the above, it is possible to conclude that the effectiveness of training
\end{abstract}


future English teachers to organize the control of educational achievements of primary school students on the basis of game technologies according to the motivational criterion is convincingly confirmed by the results of statistical processing of the results of the study.

Keywords: future teacher training; gaming technologies; control organization; motivational criterion; indicator.

\section{Introduction}

The problem of professional training of future specialists is one of the most urgent in the modern dynamic world. Society is in dire need of specialists who would be able to make not only traditional formulated solutions, but also independent non-standard solutions to professional problems. The new social order imposes new requirements to the structure and quality of specialist and worker training. Updating professional competencies and improving the level of management and teaching staff training require greater mobility and flexibility of professional development system, based on a single framework of professional skills. It is obvious that in the modern educational content the issue of professional teacher training is extremely important, which necessitates its study.

\section{Methods}

The results of the theoretical analysis (Kuanysheva, Aubakirova, Pigovayeva, Fominykh, 2019; Dudeney, 2008; Maslieva, Osadchaya, Delvig, Vdovina, 2018; Schratz, 2010; Zarudnaya, Fominykh, Enygin, Kudysheva, Epifanov, Eferova, 2018; Zubkova, Fominykh, Baranova, Abbasova, Pirozhkova, Bubenchikova, Maigeldieva, 2019; Fominykh, 2017; Fominykh, Gorbunova, 2015; Fominykh, Ekareva, Bubenchikova, 2019) of professional training problem of future teachers of Philology to the organization of the educational process and its integral component - a foreign language control in the primary school revealed the importance of this issue and, at the same time, the presence of certain problems. First, it was necessary to study and analyze the level of preparation of students of philological faculties of higher educational institutions to the organization of control in a foreign language in primary school, and then identify the criteria and indicators of future teachers' readiness to the organization of control of younger students' educational achievements in a foreign language. Gaming technology usage is the solution to the above problems will allow developing the most effective pedagogical conditions of future teacher competence formation in the optimal shape of a foreign language control in an elementary school.

One of the most important criteria for the readiness of future philologists is the motivational criterion (Chikaeva, Gorbunova, Vishnevsky, Fominykh, Gluzman, Shkuropy, Odintsova, 2019). 
Indicators of this criterion are: the interest in the search for optimal approaches to the organization of control in elementary school; understanding the necessity of taking into account psychophysiological characteristics of control subjects; understanding of the benefits of using games as a form of control in a foreign language and willingness to overcome difficulties in the organization of control in elementary school with the help of gaming technology. Let's consider the indicators of motivational criteria in more detail.

\section{Results}

Analysis of the data obtained in the study of indicators of motivational criteria revealed the following: according to the results of the survey, the majority of students had an initial / unsatisfactory level of motivation for this criterion (Lutoshkin, 1988). Among the causes of insecurity during the organization of younger pupils' educational achievement control the following issues were provided: the lack of clear methodological developments for monitoring in primary school in the teaching of philological disciplines (64\%), lack of awareness about the approaches to monitoring in elementary school.

A substantial number of students for approval "Is it important for teachers to know how to organize optimally a foreign language control in the elementary school" was selected 5 or 4 , simultaneously the same evaluation was established for the approval of the "I, if possible, avoid the use of different approaches of control in a foreign language in primary school”.

When observing the younger students' behavior during the control and conversation with students and a school psychologist with the aim to identify the level of understanding / not understanding the need to take into account the psychophysiological characteristics of the subjects of control, nobody received the highest score- 6 points, only $1 \%$ of students received 5 points, $3 \%$ of students received -4 points. The other students found it difficult to answer the question.

Regarding the color chosen by each Junior student during the control work, according to the curriculum, we note that only $1 \%$ of students chose yellow, which corresponded to +1 point and symbolized a bright mood; $9 \%$ of students chose green ( 0 points) and symbolized a calm state; $25 \%$ chose blue ( 1 point) - an unsatisfactory, sad state; $53 \%$ chose purple ( 2 points) - an anxious state; $2 \%$ chose black ( 3 points) - despondency, complete decline and $10 \%$ of students chose white $(0$ points), that is, they found it difficult to answer what their mood/state at the moment.

With regard to electives, first of all, we note that no more than $3 \%$ of Philology $3^{\text {rd }}-4^{\text {th }}$-year students and no more than $2 \%$ of fifth-year students attended electives. When explaining the reasons, they usually referred to the fact that they have more important mandatory disciplines that require a lot of time and attention. In the course of classes, students often performed tasks on their 
compulsory subjects without even trying to understand the problem. In other words, the level of understanding of the advantages of using the game in control, willingness to use game technologies and understanding of the importance of this problem among students was insufficient in the vast majority.

During the interview after elective classes, only $1 \%$ of future philologists were able to answer 5 out of 5 questions, $2.5 \%$ answered 4 questions, $3 \%$ answered 3 questions, $15 \%$ answered 2 questions and received 2 points, showing a satisfactory level of knowledge, and $78.5 \%$ found it difficult to answer questions or were able to answer 1 question, not reasoned, which indicates a lack of understanding of the benefits of using game technologies in the control process in primary school.

After a series of elective classes, students were also invited to discuss a number of issues aimed at determining the level of their readiness to use game technologies in the organization of control in their future work. The majority of students (90\%) experience difficulties in using game technologies, (87\%) consider it appropriate to avoid using the game in the educational process and, despite the fact that $43 \%$ of respondents consider themselves ready to use the game, but as the results of observations show, the level of readiness is insufficient or satisfactory.

The quantitative assessment of the level of readiness of students according to the motivational criterion is presented in the table:

Table 1. Level of students' readiness according to the motivational criterion

\begin{tabular}{ccc} 
Level & Experimental group & Control group \\
\hline Insufficient & $63.18 \%$ & $58.84 \%$ \\
\hline Satisfactory & $21.14 \%$ & $23.99 \%$ \\
\hline Reproductive & $12.46 \%$ & $14.36 \%$ \\
\hline Productive & $1.97 \%$ & $2.72 \%$
\end{tabular}

\section{Discussion}

So, the purpose of the indicator "interest in finding optimal approaches to the organization of control in primary school" was to identify the level of interest of future and young teachers in finding optimal approaches to the organization of control in primary school. The experimenter invited students to fill out forms of the questionnaire. Students had to choose the closest assessment in their opinion: 1 - completely disagree; 2 - disagree; 3 - do not have a clear opinion; 4 - agree; 5 - completely agree with the statements: 1 . I am interested in finding the best approaches to the 
organization of control in primary school; 2. I, if possible, avoid using different approaches in the organization of foreign language control in primary school; 3. I want to learn more about the approaches to the organization of control in primary school; 4. Control organization in primary school scares me; 5. It is important for teachers to know how optimally to organize the control of a foreign language in primary school; 6. I would be a better teacher if I knew how to organize the control of educational achievements of younger students better; 7. The control organization of younger pupils' educational achievements by means of game technologies takes too much time. Points were given according to the methodology of Dudeney (2008). If a student chose for the most part 5 to statements $1,3,5$ and 6 , then his level of readiness to search for optimal approaches to the organization of control in a foreign language in primary school according to the specified criterion was determined as productive/high; the chosen variant 4 to the same statements showed a reproductive/normal level. If the student chose mostly 5 to statements 2,4 and 7 , then his level of readiness was considered average/satisfactory, and the answer 4 - initial/unsatisfactory.

The next indicator is "understanding the need to take into account the psychophysiological characteristics of the subjects of control". The purpose of this indicator was to identify the level of future and young teachers understanding the need to take into account the psychophysiological characteristics of the control subjects. The experimenter offered students-philologists and school psychologist to answer a number of questions: 1) Does the organization of control of educational achievements in a foreign language in primary classes differ from the control in middle and high school? 2) Is it important for a foreign language teacher to know the psychophysiological features of the subjects of training in the organization of control? 3) In your opinion, does the form of control implementation affect its result? 4) What are the feelings of control in most of its subjects? The assessment was as follows: answering questions 1, 2 and 3, the Respondent received 1 point for the answer "I find it difficult to answer", 2 points - "no", 3 points were received for the answer "Yes". For the answer to question 4, respondents received 3 points if they gave a detailed answer to the question, 2 points were given to those who answered the question, but could not give a detailed explanation of their opinion, 1 point was given to respondents who found it difficult to answer the question without explaining the reasons.

When observing the behavior of younger students during the control, the experimenter observed the facial expressions, the mood of the subjects of control, as well as asked to draw on the control work with a colored pencil/pen a point/circle of any color that corresponds to the mood of the child at that moment. At the same time, the experimenter used the color matrix of Lutoshkin (1988), in which each color corresponds to the emotional state of a person at the time of testing. The theoretical basis of this technique is the idea that the attitude to certain people, events, objects or phenomena is 


\section{Dictum Factum}

reflected in the color associations to them. That is, each color of the spectrum is a conditional sign of a certain mood: red - enthusiastic; orange - joyful, warm; yellow - bright, pleasant; green calm, balanced; blue - unsatisfactory, sad; purple - anxious, tense; black - complete decline, despondency; white - symbolizes the answer type: "It is difficult to say".

Interpretation of the color matrix results requires quantification of the obtained data: numerical transformation of estimates. The score symbolizes the intensity of emotional states: red -+3 points; orange -+2 points; yellow -+1 point; green -0 points; blue -1 point; purple -2 points; black -3 points; white -0 points.

The next indicator had the purpose to identify future and young teacher level of understanding of the benefits of using games as a form of control in a foreign language (Murtazina, 2018). The experimenter suggested that philology students attend elective classes on topics:

- modern control requirements;

- primary school student as a subject of educational activities in a foreign language;

- psycho-physiological features of the younger student as a subject of training and control in a foreign language;

- leading motives of primary school students;

- features of Junior high school games;

- game as a form of control of foreign language communicative competence of younger students;

- structure and content of a complex scenario game as a form of thematic and final control;

- structural components of game exercises with role component.

After a series of elective classes students were invited to discuss a number of issues:

1. What are the most important requirements for the organization of control in primary school, in your opinion?

2. What is the peculiarity of primary school age in terms of leading activities?

3. Why is the game considered the best form of learning a foreign language in primary school?

4. Does the organization of training and control affect the new mental states of younger students? 
5. What types of games would you use in the educational process in a foreign language? Why? While observing the philology students in elective classes, the examiner monitored the attendance and asked to explain the reasons for the absence/presence at each of them. In addition, he observed the involvement of students in the educational process, their interest and behavior at the lecture.

During the interview, the student received 5 points for a reasoned answer to all 5 questions, 4 points for 4 questions, 3 points for 3 answers, 2 points for 2 answers, 1 point for answering only 1 question, if the student found it difficult to answer the question -0 points.

The last indicator of the motivational criterion was "readiness to overcome difficulties in the organization of control in primary school with the help of game technologies". Its purpose was to identify the level of understanding of the advantages of using the game as a form of control in a foreign language among future and young teachers (Chikaeva et al., 2019; Schratz, 2010). As with the assessment of the previous indicator during the observation of philology students during elective classes, the examiner followed the attendance and asked to explain the reasons for the absence/presence at each of them. In addition, he observed the involvement of students in the educational process, their interest and behavior at the lecture.

During the interview, the student received 3 points for a reasoned answer to 1 question, 1 point for 2 and 3 questions, if the student found it difficult to answer the question or could not explain the reason for his answer -0 points.

\section{Conclusion}

Thus, as the data shows, the vast majority of respondents revealed an insufficient level of readiness within the motivational criterion: respectively, $63.18 \%$ in the experimental and $58.84 \%$ - in the control groups. $21.14 \%$ of respondents of experimental and $23.99 \%$ of future teachers-philologists of control group corresponded to satisfactory level. Reproductive level was demonstrated by $12.45 \%$ of experimental students and $14.36 \%$ of control group respondents. The productive level of readiness according to the above criterion was recorded in $1.97 \%$ of future teachers of the experimental and $2.72 \%$ of the control group. To sum up the mentioned above, we can conclude that chosen model of future philologists' readiness formation is correct and well-developed, as experimental results proved.

\section{References}

Chikaeva, K.S., Gorbunova, N.V., Vishnevsky, V.A., Fominykh, N.Y., Gluzman, Y.V., Shkuropy, O.I., Odintsova, V.I. (2019). Corporate Culture of Educational Organization as a Factor of 
Influencing the Social Health of the Russian Student Youth. Revista Praxis Educational, 15(36), 583-598.

Dudeney, G. (2008). How to Teach English with Technology. Pearson Longman.

Fominykh, N.Y. (2017). The role of pedagogical design in the professional activity of a foreign language teacher. Strategy and tactics of training a modern teacher in a dialog space of education. Collection of scientific articles, 258-263.

Fominykh, N.Y., Ekareva, I.L., Bubenchikova, A.V. (2019). Essence of professional activity of a technical translator in the information society. Modern pedagogical education, 2, 80-84.

Fominykh, N.Y., Gorbunova, N.V. (2015). Trends in the development of a computer-oriented environment for foreign-language professional training of future specialists in the field of computer science and engineering. Bulletin of Cherepovets State University, 6(67), 117-122.

Kuanysheva, B.T., Aubakirova, R.Z., Pigovayeva, N.Y., Fominykh, N.Y. (2019). Technologization of the Pedagogical Process as a Teacher Self-Improvement Factor. Journal of Social Studies Education Research, 10, 404-433.

Lutoshkin, A.N. (1988). Emotional color painting. Retrieved from: https://studfiles.net/preview/1790803/

Maslieva, Y.S., Osadchaya, I.Y., Delvig, N.A., Vdovina, N.V. (2018). Approaches to future teachers' professional training to the organization of a foreign language assessment at primary schools. The Journal of Social Sciences Research, 1, 148-153.

Murtazina, E.I. (2018). Development of technical University students tolerance in the process of foreign language training: author's abstract. Kazan.

Schratz, M. (2010). What is a European Teacher? Retrieved from: http://entep.bildung.hessen.de/news-Dateien/Entep_BOOK-2010.pdf

Zarudnaya, M.V., Fominykh, N.Y., Enygin, D.V., Kudysheva, A.A., Epifanov, D.A., Eferova, A.R. (2018). Methodological Approaches to University Instructors Professional Foreign Languages Competence Development. The Journal of Social Sciences Research, 5, 375-381.

Zubkova, M.A., Fominykh, N.Y., Baranova, E.N., Abbasova, L.I., Pirozhkova, A.O., Bubenchikova, A.V., Maigeldieva, S.M. (2019). Approaches to the future engineers foreign communicative culture formation. Humanities and Social Sciences Reviews, 7(4), 781-786. 